\title{
Triptan use after starting prophylactic migraine treatment: $A$ retrospective cohort study in a primary care population
}

2014, Vol. 34(II) 927-932

(C) International Headache Society 2014

Reprints and permissions:

sagepub.co.uk/journalsPermissions.nav DOI: 10.1 | 77/03331024|45215। I

cep.sagepub.com

@SAGE

\section{Antonia FH Smelt' ${ }^{1}$, Willem JJ Assendelft ${ }^{1,2}$, Christel E van Dijk ${ }^{3}$ and Jeanet W Blom'}

\begin{abstract}
Background: Clinical trials on the prophylactic effect of propranolol and metoprolol for migraine show that starting this medication leads to a decrease in the use of attack medication of 0.9-8.9 doses per month. However, studies in daily practice are lacking.

Methods: We compared the number of triptans prescribed in the six months before and the six months after the start of propranolol/metoprolol in a Dutch national representative primary care cohort.

Results: Of the 168 triptan-using patients who started with propranolol or metoprolol, the number of triptans prescribed before starting was 4.6 doses per month. The number of triptans prescribed six months before compared with six months after starting propranolol/metoprolol decreased with 1.0 dose per month (Wilcoxon rank test; $p=0.000$ ). Conclusion: In this primary care population, although the number of triptans prescribed decreased after starting propranolol or metoprolol, the decrease is relatively small compared to data from clinical trials.
\end{abstract}

\section{Keywords}

Migraine, triptans, preventive medication, effectiveness, primary care

Date received: 28 November 20I3; revised: 2 January 20I4; accepted: 3 January 2014

\section{Introduction}

Migraine is a chronic episodic disorder characterized by headache attacks accompanied by neurological, gastrointestinal and autonomic symptoms (1-3). Patients with frequent and severe migraine attacks can be prescribed prophylactic medication to reduce the frequency, duration, and severity of attacks. Clinical trials on the prophylactic effect of propranolol and metoprolol show divergent results concerning the magnitude of decrease in use of attack medication after starting these medications. The results from trials range from a decrease of 0.9 to 8.9 doses/month (4-9) (see online Appendix 1).

Studies on the effectiveness of this prophylactic medication in daily practice are needed to get an idea of the effect of prophylactic medication in daily practice. However, very few such studies have been conducted (10). Therefore, it is unclear whether prophylactic medication in daily practice will lead to a decrease in the use of attack medication and, if it does, what the magnitude of its effect is on the use of attack medication.

This study aims to elucidate whether starting prophylactic migraine treatment with propranolol or metoprolol leads to a decrease in the use of attack medication in daily clinical practice and to determine the magnitude of the effect.

\footnotetext{
'Department of Public Health and Primary Care, Leiden University Medical Center, the Netherlands

${ }^{2}$ Department of Primary and Community Care, Radboud University Medical Center, the Netherlands

${ }^{3}$ NIVEL Netherlands Institute for Health Services Research, the Netherlands
}

\section{Corresponding author:}

Antonia FH Smelt, Leiden University Medical Center, Department of Public Health and Primary Care (V-0-P), PO Box 9600, RC Leiden 2300, the Netherlands.

Email: a.f.h.smelt@lumc.nl 


\section{Methods}

\section{Study design}

We performed a retrospective cohort study in a primary care population in which we compared triptan prescriptions in the six months before and the six months after starting prophylactic treatment with propranolol or metoprolol. These two agents were selected because these are the most frequently used prophylactic medications. Also, we decided to focus on triptans as attack medication because in the Netherlands this medication is available only by prescription from a physician. Triptan prescriptions were used as a proxy for use, because we had no data on actual medication use.

\section{Study population}

We retrieved the study population from the electronic medical records (EMRs) of general practices that participated in the NIVEL Primary Care Database, which is a representative sample of 87 general practices and approximately 350,000 patients in the Netherlands $(11,12)$. The NIVEL database is run by the Netherlands Institute for Health Services Research (NIVEL) and contains longitudinal data at the patient level in terms of contacts, morbidity (International Classification of Primary Care; ICPC) (13)) and prescriptions. There are small yearly changes in practice composition. The NIVEL database is registered with the Dutch Data Protection Authority; data are handled according to national data protection guidelines (anonymous patient records and opt-out). In the Netherlands, this makes ethical approval by an ethics committee not necessary $(14,15)$.

The patient sample consisted of three cohorts that were followed for three years, each starting in subsequent years: i.e. 2006 (cohort 1), 2007 (cohort 2) and 2008 (cohort 3 ). We selected patients aged $\geq 18$ years who received one or more prescriptions for triptans available in the Netherlands (almotriptan, eletriptan, frovatriptan, naratriptan, rizatriptan, sumatriptan, or zolmitriptan) during the first year (2006, 2007 and 2008, respectively). From these patients we extracted prescription data of patients for each cohort for three consecutive years, namely the first year and the two subsequent years.

\section{Data analyses}

Figure 1 presents an overview of the subsequent analyses. First, for an impression of the natural variation in the number of triptans prescribed in the entire study group, we calculated the difference in triptan use between the first half year and second half year of the

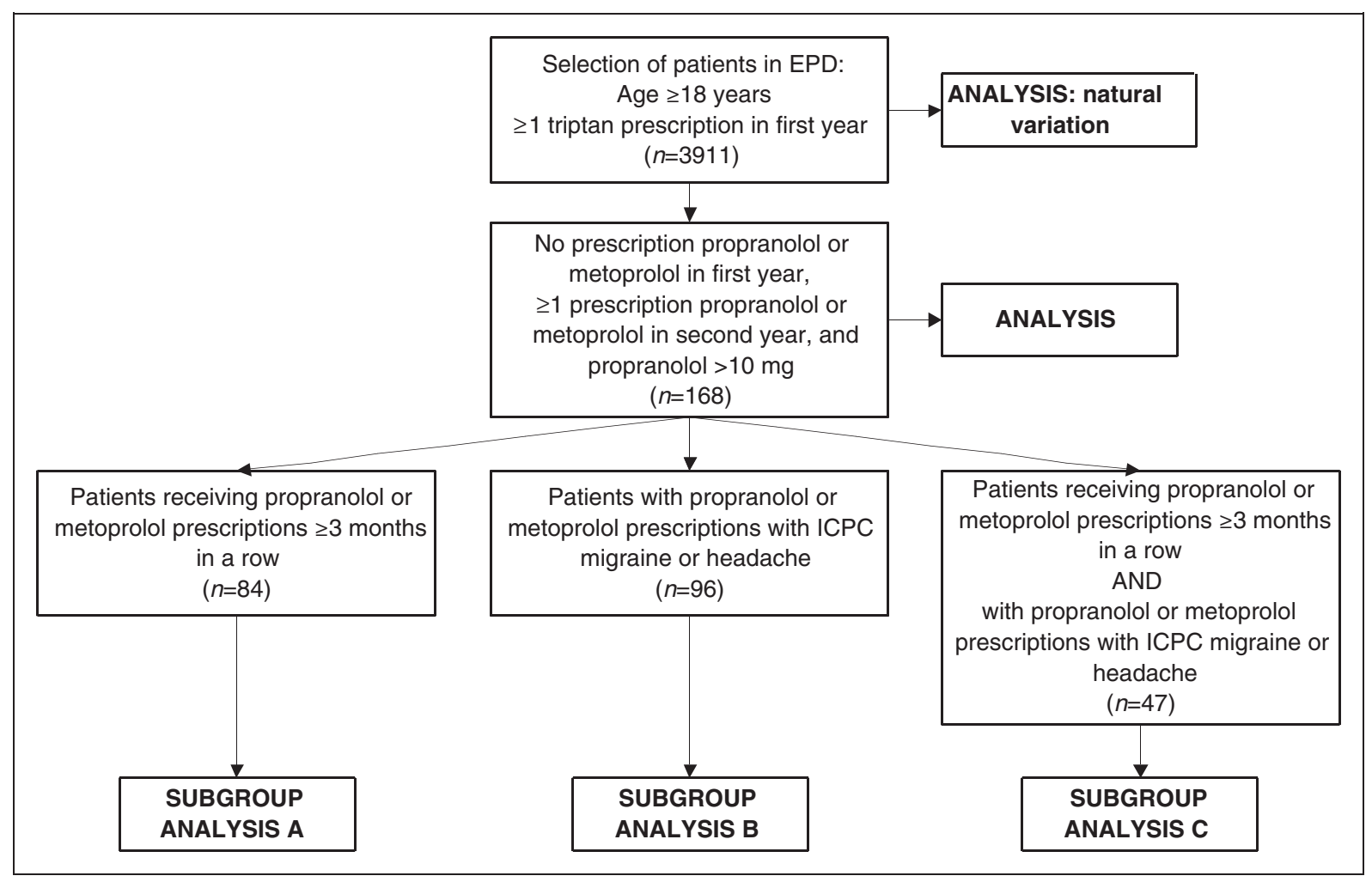

Figure I. Flowchart of the composition of the study group and the analyses performed. 
middle year (index year) for all patients with complete prescription data.

Then, we combined the cohorts and continued with all patients who started with propranolol or metoprolol in the second year. We did not use data from patients who received prescriptions for propranolol $10 \mathrm{mg}$. In case of missing values in the number of prescriptions, we used imputation of the mean number of tablets from other prescriptions. Then, we calculated the mean number of triptans prescribed per month in the six months before and the six months after the start of propranolol or metoprolol, and tested whether the decrease in the number of triptans prescribed was significant. Because the data were paired but not normally distributed, we used a two-sided Wilcoxon rank test, with an a priori alpha level 0.05 . We performed an additional multilevel Poisson regression analysis to check for potential confounding by age, sex and general practice.

We planned three subgroup analyses. Subgroup A consisted of patients who received prescriptions for propranolol or metoprolol for at least three consecutive months. Subgroup B consisted of patients for whom the propranolol or metoprolol prescription had the ICPC code migraine (N89) or headache (N01). Subgroup C was a combination of both (patients who received propranolol or metoprolol for at least three consecutive months and a prescription with ICPC code N89 or N01).

Statistical analyses were performed with the SPSS. We did not adjust for multiple testing.

\section{Results}

We selected 3911 patients (1567 in cohort 1, 1212 in cohort 2, and 1132 in cohort 3) who received at least one triptan prescription in the first year. This roughly corresponds with a percentage of $1 \%$ of the total population using a triptan out of a total population of 116,489 (cohort 1), 109,331 (cohort 2) and 110,818 (cohort 3) patients.

Investigation of the natural variation in triptans prescribed in 3345 of 3911 patients $(86 \%)$ with complete prescription data revealed that the number of triptans prescribed did not fluctuate between the first and second half year of our index year. The mean number of triptans prescribed per month in the first half year was 2.91 (SD 5.4). In the second half year the number of triptans prescribed per month increased by 0.05 (SD: 3.5) (difference not significant) (Wilcoxon rank test; $p=0.391)$.

In total, 168 of 3911 patients $(4.3 \%)$ received no prescription for metoprolol or propranolol in the first year, and at least one prescription for propranolol or metoprolol in the second year of follow-up (Table 1).
Of all triptan prescriptions, 3\% (106 of 3269) did not include the number of doses. In these cases we used imputation of the mean number of tablets from other prescriptions.

In Table 2 we show the change in triptan prescriptions over the course of time. Table 3 shows triptan use in the six months before and the six months after the start of propranolol or metoprolol. During the six months before the start of propranolol/metoprolol the mean number of triptans prescribed per month was 4.6, whereas during the six months after the start the mean number was 3.6. The mean difference in the doses of triptans prescribed per month between the six months before and six months after the start of propranolol or metoprolol was -1.0 triptans per month (Wilcoxon rank test; $p=0.000$ ). This difference was somewhat larger in subgroup A of patients who received consecutive prescriptions for propranolol or metoprolol for at least three months, namely 1.3 triptan doses per month. In subgroup B of patients for whom the propranolol or metoprolol prescription had the ICPC code for migraine or headache, the decrease was 0.9 tablets/ month. After combining these two categories (subgroup C), the difference increased to 1.6 triptan doses per month.

The multilevel Poisson regression analysis yielded results similar to the initial analysis, indicating that a confounding effect of age, sex and general practice was not present (data not shown).

\section{Discussion}

This retrospective cohort study shows that, after starting prophylactic treatment with propranolol or metoprolol in daily practice, the number of triptans prescribed decreased by 1.0 to 1.6 doses per month. This decrease in triptan use cannot be attributed to normal fluctuation.

We found a percentage of triptan users in the normal population of $1.0 \%$, which is comparable to the percentage found in an earlier study in a large Dutch primary care database (15). Also, the number of 168 $(4.4 \%)$ patients out of 3811 triptan users starting preventive treatment with propranolol or metoprolol is as we would expect from earlier research (16).

There are some limitations to this study. We lack information on actual medication use by patients, since we had only prescription data from the general practitioner's electronic medical record. However, we assume patients were taking the medication, as the vast majority received several prescriptions in a row. Also, a sensitivity analysis spreading the use of triptans over the period until the next prescription showed no difference compared with the reported results (see online Appendix 2). Secondly, we had no data on the 
Table I. Baseline characteristics of the three cohorts of migraine patients who started treatment with propranolol or metoprolol. Values are means (SD) unless stated otherwise.

\begin{tabular}{|c|c|c|c|c|}
\hline & $\begin{array}{l}\text { Cohort I } \\
2006-2008 \\
(N=62)\end{array}$ & $\begin{array}{l}\text { Cohort } 2 \\
2007-2009 \\
(N=44)\end{array}$ & $\begin{array}{l}\text { Cohort } 3 \\
2008-2010 \\
(N=62)\end{array}$ & $\begin{array}{l}\text { Total group } \\
(N=168)\end{array}$ \\
\hline Female (\%) & 81 & 84 & 84 & 83 \\
\hline Age in years & $44.8(12.1)$ & $43.5(9.2)$ & $44.6(13.7)$ & $44.4(12.0)$ \\
\hline $\begin{array}{l}\text { Number of triptans per months during } \\
\text { the year before starting beta-blocker } \\
\text { (IQR) }\end{array}$ & $4.7(1.0 ; 6.7)$ & $4.2(0.9 ; 5.5)$ & $4.0(0.5 ; 5.0)$ & $4.3(0.0 ; 22.5)$ \\
\hline $\begin{array}{l}\text { Propranolol or metoprolol } \geq 3 \text { months } \\
\quad(\%)\end{array}$ & 52 & 39 & 57 & 50 \\
\hline $\begin{array}{l}\text { Propranolol or metoprolol continued } \\
\text { until end of period (\% of patients } \\
\text { who used propranolol or metoprolol } \\
\geq 3 \text { months) }\end{array}$ & 50 & 59 & 57 & 55 \\
\hline \multicolumn{5}{|l|}{ Dosage of beta-blocker ${ }^{a}(\%)$} \\
\hline $\begin{array}{l}\text { Low dosage (propranolol } 40 \mathrm{mg} \text { or } \\
\text { metoprolol } 50 \mathrm{mg} \text { per day) }\end{array}$ & 31.1 & 36.8 & 23.1 & 32.1 \\
\hline $\begin{array}{l}\text { Middle high dosage (propranolol } \\
80 \mathrm{mg} \text { or metoprolol } 100 \mathrm{mg} \text { per day) }\end{array}$ & 57.4 & 39.5 & 46.2 & 50.0 \\
\hline $\begin{array}{l}\text { High dosage (propranolol } 160 \mathrm{mg} \text { or } \\
\text { metoprolol } 200 \mathrm{mg} \text { ) }\end{array}$ & 4.9 & 15.8 & 23.1 & 10.7 \\
\hline Combination of different dosages & 6.6 & 7.9 & 7.7 & 7.1 \\
\hline \multicolumn{5}{|l|}{$\begin{array}{l}\text { ICPC coding of indication for pro- } \\
\text { pranolol or metoprolol (\%) }\end{array}$} \\
\hline N89 (Migraine) & 59.7 & 61.4 & 38.7 & 52.4 \\
\hline Nol (Headache) & 1.6 & 2.3 & 4.8 & 3.0 \\
\hline K (Circulatory) & 24.2 & 20.5 & 25.8 & 23.8 \\
\hline P (Psychological problems) & 3.2 & 4.5 & 6.5 & 4.8 \\
\hline
\end{tabular}

IQR: interquartile range; ICPC: International Classification of Primary Care. ${ }^{a}$ Data for dosages of beta-blockers known for $66.7 \%$ of patients (cohort I $n=61$, cohort $2 n=38$ cohort $3 n=13$ ).

Table 2. Number of triptan prescriptions per month. Numbers are means (SD).

\begin{tabular}{lllll}
\hline & $\begin{array}{l}\text { Baseline; six } \\
\text { months before start } \\
\text { beta blocker }(n=168)\end{array}$ & $\begin{array}{l}\text { One to three } \\
\text { months after starting } \\
\text { beta-blocker }(n=168)\end{array}$ & $\begin{array}{l}\text { Three to six } \\
\text { months after starting } \\
\text { beta-blocker }\left(n=84^{\mathrm{a}}\right)\end{array}$ & $\begin{array}{l}\text { Six to nine } \\
\text { months after starting } \\
\text { beta-blocker }\left(n=84^{\mathrm{a}}\right)\end{array}$ \\
\hline Total group & $4.6(5.2)$ & $3.9(6.8)$ & $3.7(5.1)$ & $3.7(5.1)$
\end{tabular}

${ }^{\mathrm{a}}$ Patients who continued beta blocker for more than three months.

use of other attack medication (e.g. paracetamol or nonsteroidal anti-inflammatory drugs (NSAIDs)). Use of such medications might have concurrently decreased, or might have increased. However, in the current study, because triptan use decreased after starting propranolol or metoprolol, we can assume that migraine attacks were less frequent and/or severe. Thirdly, we had no data on prescriptions that patients may have received from a neurologist. Nevertheless, this is unlikely to have had a marked effect on our results because in the Netherlands $95 \%$ of triptan prescriptions are issued by general practitioners (17).

To our knowledge, this is the first study to evaluate the effect of propranolol and metoprolol on the use of attack medication in daily practice of primary care. It appears that starting with propranolol or metoprolol indeed leads to a decreased use of attack medication. However, compared with clinical trials this decrease is lower than expected. This difference is probably partially due to the fact that patients with more frequent 
Table 3. Mean number (standard error of the mean) of triptans prescribed per month in the six months before start of propranolol/ metoprolol compared with the mean number of triptans prescribed per month in the six months after start of this medication.

\begin{tabular}{|c|c|c|c|c|}
\hline & $\begin{array}{l}\text { No. of triptans prescribed } \\
\text { per month in the six } \\
\text { months before starting } \\
\text { propranolol/metoprolol }\end{array}$ & $\begin{array}{l}\text { No. of triptans prescribed } \\
\text { per month, in the six } \\
\text { months after starting } \\
\text { propranolol/metoprolol }\end{array}$ & $\begin{array}{l}\text { Difference } \\
\text { between before } \\
\text { and after }\end{array}$ & $p$ value $^{a}$ \\
\hline Total group $(n=168)$ & $4.6(0.40)$ & $3.6(0.40)$ & -1.0 & 0.000 \\
\hline $\begin{array}{l}\text { Subgroup a: Propranolol/ } \\
\text { metoprolol for } \geq 3 \text { months } \\
(n=84)\end{array}$ & $5.1(0.61)$ & $3.8(0.64)$ & -1.3 & 0.004 \\
\hline $\begin{array}{l}\text { Subgroup b: ICPC migraine or } \\
\text { headache }(n=96)\end{array}$ & $5.5(0.58)$ & $4.6(0.6 I)$ & -0.9 & 0.013 \\
\hline $\begin{array}{l}\text { Subgroup c: Propranolol/ } \\
\text { metoprolol for } \geq 3 \text { months } \\
\text { and ICPC migraine or head- } \\
\text { ache }(n=47)\end{array}$ & $5.8(0.88)$ & $4.2(0.98)$ & -1.6 & 0.008 \\
\hline
\end{tabular}

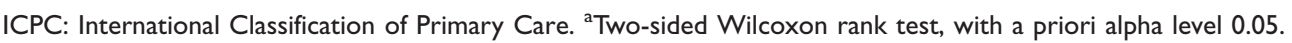

and/or severe migraine attacks are recruited for clinical trials and have more room for improvement. Also, in our study we could not validly include the use of other analgesics and NSAIDs (which in the Netherlands are mainly dispensed over the counter), which might have concurrently decreased (in our opinion most likely), or might have increased (least likely). Moreover, bias in the trials may have played a role as, especially in the propranolol trials, an intention-to-treat analysis was not always performed (4). Consequently, these trials report only on the most compliant patients, a patient group that is not representative for daily practice. Thus, clinical trials do not always provide information on the effect of medication in actual clinical practice. Therefore, we strongly believe that studies such as the present one are needed to determine this effect.

\section{Conclusions}

We found that during the six months after starting preventive treatment with propranolol or metoprolol there was a decrease in the number of triptans prescribed of 1.0 to 1.6 triptans per month. Hence, we can conclude that starting with propranolol or metoprolol in daily practice indeed leads to a decrease in frequency and/or severity of migraine attacks. However, compared with data from trials, this decrease is smaller than expected. This underlines the importance of studies specifically designed to evaluate the effect of headache treatment in daily practice.

\section{Clinical implications}

- Studies on the prophylactic effect of propranolol and metoprolol on the use of attack medication in daily practice are lacking.

- In this primary care population, the number of triptans prescribed decreased after starting propranolol or metoprolol, but the decrease is small compared with data from clinical trials.

- It is important to perform specially designed studies in which the effect of headache treatment is evaluated in daily practice.

\section{Funding}

This research received no specific grant from any funding agency in the public, commercial, or not-for-profit sectors.

\section{Conflict of interest}

None declared.

\section{References}

1. Brown JS, Neumann PJ, Papadopoulos G, et al. Migraine frequency and health utilities: Findings from a multisite survey. Value Health 2008; 11: 315-321.

2. Lipton RB, Bigal ME, Diamond M, et al. Migraine prevalence, disease burden, and the need for preventive therapy. Neurology 2007; 68: 343-349. 
3. Terwindt GM, Ferrari MD, Tijhuis M, et al. The impact of migraine on quality of life in the general population: The GEM study. Neurology 2000; 55: 624-629.

4. Linde K and Rossnagel K. Propranolol for migraine prophylaxis. Cochrane Database Syst Rev 2004; 2: CD003225.

5. Olsson JE, Behring HC, Forssman B, et al. Metoprolol and propranolol in migraine prophylaxis: A doubleblind multicentre study. Acta Neurol Scand 1984; 70: $160-168$.

6. Andersson PG, Dahl S, Hansen JH, et al. Prophylactic treatment of classical and non-classical migraine with metoprolol - a comparison with placebo. Cephalalgia 1983; 3: 207-212.

7. Vilming S, Standnes B and Hedman C. Metoprolol and pizotifen in the prophylactic treatment of classical and common migraine. A double-blind investigation. Cephalalgia 1985; 5: 17-23.

8. Louis P, Schoenen J and Hedman C. Metoprolol v. clonidine in the prophylactic treatment of migraine. Cephalalgia 1985; 5: 159-165.

9. Kangasniemi P, Andersen AR, Andersson PG, et al. Classic migraine: Effective prophylaxis with metoprolol. Cephalalgia 1987; 7: 231-238.

10. Smelt AF, Blom JW, Dekker F, et al. A proactive approach to migraine in primary care: A pragmatic randomized controlled trial. CMAJ 2012; 184: E224-E231.
11. Braspenning J, Wichers L and Faber M. Praktijkvoering LINH-praktijken representatief. Huisarts en Wetenschap 2007; 4: 133.

12. Stirbu-Wagner I, Dorsman SA, Visscher S, et al. Landelijk Informatienetwerk Huisartsenzorg. Feiten en cijfers over huisartsenzorg in Nederland [Netherlands Information Network of General Practice: Facts and figures of general practice in the Netherlands]. Utrecht/ Nijmegen: NIVEL/IQ, http://www.LINH.nl. 2012 (accessed 20 November 2013).

13. Lamberts $\mathrm{H}$ and Wood M. International Classification of Primary Care (ICPC). Oxford: Oxford University Press, 1990.

14. Schellevis F. Medisch-etische toetsing van observationeel onderzoek: Een grijs gebied. Huisarts en Wetenschap 2006; 49: 13513-13516.

15. Netherlands Institute for Health Services ResearchNIVEL Primary Care Database, http://www.nivel.nl/en/ dossier/nivel-primary-care-database (accessed 20 November 2013).

16. Westerd GP, Hoonhout L, de Bakker DH, et al. Huisarten met en zonder elektronisch medisch dossier: Weinig verschil in medisch handelen. Huisarts en Wetenschap 2002; 45: 58-62.

17. Dekker F, Wiendels NJ, de Valk V, et al. Triptan overuse in the Dutch general population: A nationwide pharmaco-epidemiology database analysis in 6.7 million people. Cephalalgia 2011; 31: 943-952. 